\title{
ENTRE A COMUNICAÇÃO COMPETENTE E A DISTORÇÃO COMUNICATIVA: ESTUDO DAS SEMELHANÇAS NAS EMBALAGENS DE IOGURTE E BEBIDA LÁCTEA FERMENTADA
}

\section{AMONG THE COMPETENT COMMUNICATION AND COMMUNICATIVE DISTORTION: A STUDY OF SIMILARITIES IN YOGURT AND FERMENTED MILK DRINKS PACKAGINGS}

\author{
Kelly Carvalho Vieira \\ Professora do Curso de Administração da Universidade Federal de Viçosa - Campus Florestal \\ Florestal, MG, Brasil \\ E-mail: kellycarvalho1108@hotmail.com \\ Valderí de Castro Alcântara \\ Doutorando do Departamento de Economia e Administração - DAE - Universidade Federal de Lavras (UFLA) \\ Florestal, MG, Brasil \\ E-mail: valderidecastroalcantara@gmail.com \\ Cintia Loos Pinto \\ Professora do Curso de Administração da Universidade Federal de Viçosa - Campus Florestal \\ Florestal, MG, Brasil \\ E-mail: cintialoosp@gmail.com \\ José Willer do Prado \\ Mestrando do Departamento de Economia e Administração - DAE - Universidade Federal de Lavras (UFLA) \\ Lavras, MG, Brasil \\ E-mail: jwprado@gmail.com \\ André Luiz de Paiva \\ Mestrando do Departamento de Economia e Administração - DAE - Universidade Federal de Lavras (UFLA) \\ Lavras, MG, Brasil \\ E-mail: andrepaiva2@gmail.com
}

\section{RESUMO}

Neste artigo objetivamos interpretar se as semelhanças entre as embalagens de iogurte e bebida láctea fermentada são efeitos de uma comunicação competente ou de uma distorção no processo de compra desses produtos. A pesquisa é qualitativa, os dados foram coletados por meio de entrevistas e as análises realizadas conforme $o$ modelo da pragmática-formal. As distorções e confusões encontradas parecem ser deliberadas por parte das empresas, orientadas por ações estratégicas que vendem produtos diferentes com trade dress semelhantes. A pretensão da correção normativa (aspectos legais) foi a menos criticada, as demais como verdade, sinceridade/veracidade, inteligibilidade/compreensibilidade

consideradas distorcidas e confusas pelos consumidores. Indicamos que pela análise as comunicações se afastam do modelo competente no seu relacionamento com os consumidores e que a perspectiva formal-pragmática pode auxiliar na orientação de normatizações que democraticamente instituam mecanismos que protejam o consumidor de ações estratégicas pautadas na comunicação distorcida, manipulação e confusão.

Palavras-chave: Embalagens. Comunicação. Distorção. Habermas. Marketing.

Data de submissão: 6 de janeiro de 2016.

\section{ABSTRACT}

This article aimed to interpret if the similarities between the packaging of yogurt and fermented milk drink are effects of a competent communication or a distortion in the process of purchasing these products. The research is qualitative, the data was collected through interviews and the analyzes were performed according to the pragmatic-formal model. The distortions and confusions found appear to be deliberated on the part of businesses, guided by strategic actions that sell different products with similar trade dresses. The claim of normative correction (legal aspects) was the least criticized whereas the other as truth, honesty/truthfulness, intelligibility/comprehensibility are considered distorted and confused by the consumers. We note that, by the analysis, the communications depart from the competent model in their relationship with consumers and that the perspective of formalpragmatic can assist in guiding regulations that democratically institute mechanisms that protect consumers of strategic actions based on distorted communication, manipulation and confusion.

Keywords: Packaging. Communication. Distortion. Habermas. Marketing.

Data de aprovação: 24 de setembro de 2018. 


\section{INTRODUÇÃO}

O marketing possui papel importante nas relações entre consumo e sociedade. Essas relações muitas vezes carecem de uma análise reflexiva e pautada para a visão dos diversos participantes das práticas de consumo. Dessa forma, este artigo coloca o marketing, em especial, a temática da influência das embalagens no comportamento de compra, sob o olhar da pragmática-formal do filósofo Jürgen Habermas. Um olhar crítico-normativo que contribui para pensar, na prática, a relação dos consumidores e fabricantes com as embalagens e sua função comunicacional, que se revela nas tensões entre uma comunicação competente e a distorção comunicativa, ou de outra forma, entre o uso comunicativo e estratégico (e instrumental) da linguagem.

Destacamos que no marketing, a utilização do referencial habermasiano é incipiente (UNDERWOOD; OZANNE, 1998; VIEIRA et al., 2002). Nesse sentido mesmo com o movimento Rethinking Marketing da década de 1990 que procurava pensar o marketing de forma crítica ainda permanecem visões técnicas e voltadas para a persuasão dos consumidores (BROWNLIE et al., 1994; FARIA, 2006). Adiante, para Underwood e Ozanne (1998) a produção intelectual de Habermas oferece contribuições interdisciplinares em pesquisas sobre o papel comunicativo das embalagens. Alvesson (1994) também destaca a importância do autor para estudar e criticar o uso de técnicas que podem distorcer a percepção dos consumidores. Argumentamos neste texto que a linguagem e a comunicação em marketing se estabelecem nas tensões entre a persuasão/manipulação/distorção/confusão (formas estratégicas no sentido habermasiano) e a compreensão/informação/entendimento (formas comunicativas). Todavia, as ações de marketing são predominantemente voltadas para as primeiras formas (UNDERWOOD; OZANNE, 1998; BERTOLDO, 2006; MICELI; PIETERS, 2010; VAN HOREN; PIETERS, 2012; VIEIRA et al., 2015).

No mercado de laticínios, as embalagens de iogurtes e de bebidas lácteas fermentadas são aparentemente semelhantes e podem causar distorções ao processo comunicativo. A produção de bebidas lácteas fermentadas é uma das principais opções para o aproveitamento do soro do leite - com fornecimento gratuito ou de baixo custo (LIZIEIRE; CAMPOS, 2001). Nesse contexto, a bebida láctea fermentada tem ganhado grande importância no processo produtivo, reduzindo o custo total dos ingredientes, uma vez que utiliza soro de leite e ainda mantém uma linha de produção semelhante a do iogurte. Assim, a bebida láctea e o iogurte possuem características sensoriais e embalagens muito semelhantes, porém em termos nutricionais há diferenças (ABREU; GAJO, 2012). Logo, o locus de investigação parte da 'indicação' de que no ambiente de varejo as embalagens de bebida láctea fermentada e iogurte podem causar processos distorcidos de comunicação, envolvendo a confusão nos processos de compra.

Portanto, este artigo objetiva interpretar se as semelhanças entre as embalagens de iogurte e bebida láctea fermentada são efeitos de uma comunicação competente ou de uma distorção no processo de compra desses produtos. Especificamente, buscamos apresentar também como os consumidores reajem diante de informações sobre as diferenças entre iogurte e bebida láctea fermentada.

A seguir, apresentamos discussões sobre o papel das embalagens, trade dress, confusão do consumidor e o modelo de comunicação competente. Na metodologia, os procedimentos de coleta e análise dos dados. Em seguida, resultados e discussão, e, por fim, as conclusões com recomendações, limitações e uma agenda de pesquisas futuras. 


\section{REFERENCIAL TEÓRICO}

\section{Embalagens e seu potencial comunicativo}

Atributos da embalagem como o aspecto visual (cor, figuras, marca) e informativo (informação nutricional, peso, data de validade, lista de ingredientes, entre outros) são considerados relevantes no comportamento de consumo, em especial, de alimentos (VIEIRA et al., 2015). Chandon e Wansink (2011) consideram que a embalagem pode diferenciar uma marca no momento mais importante da decisão de compra: no ponto de venda, onde as embalagens podem reforçar a imagem do produto, destacando-o na prateleira e atraindo a atenção do consumidor (GHIDOSSI et al., 2012; VIEIRA; ALCÂNTARA; TONELLI, 2014). Logo, a embalagem não possui apenas a função prática de proteger o produto, mas possui também a função de comunicar conteúdos, podendo ainda influenciar hábitos de consumo de alimentos (CHANDON; WANSINK, 2011).

Vieira, Alcântara e Tonelli (2014) destacam que os debates sobre embalagens de alimentos envolvem diversos temas como a importância econômica, social e ambiental, consumo consciente e saudável, estratégias de comunicação em marketing e impactos na saúde. Assim, na revisão realizada os autores identificaram, por um lado, efeitos negativos relacionados a embalagem como alergias, contaminações, obesidade e tabagismo, e, por outro, que as embalagens podem influenciar hábitos conscientes de consumo. Portanto, as empresas utilizam das embalagens de diversas formas, tanto no sentido informacional e comunicativo (forma consciente e ética na comunicação com o consumidor) e também como meio de persuasão e manipulação (UNDERWOOD; OZANNE, 1998). E, estes casos podem ser analisados em pesquisas empíricas.

Para pensar essas possibilidades podemos utilizar do conceito de trade dress que se relaciona com a forma de apresentação dos produtos (CARDOSO; BERTOLDO, 2012).

Consiste num conjunto de características, que pode incluir, entre outras, uma cor ou esquema de cores, forma, embalagem, configuração do produto, sinais, frases, disposição, estilização e tamanho de letras, gráficos, desenhos, emblemas, brasões, texturas e enfeites ou ornamentos, capazes de identificar determinado produto ou diferenciá-lo dos demais (DANIEL, 2006, p. 1 ).

Em decorrência da importância econômica do trade dress, ele pode ser objeto de reprodução total ou parcial por outras empresas/marcas que se valem do fato de o público consumidor já reconhecer e identificar aquela apresentação visual (BERTOLDO, 2006). Para Bertoldo (2006), as empresas se aproveitam do prestígio do trade dress de outros produtos.

Do ponto de vista do consumidor, as marcas imitadoras ou outras que utilizam das embalagens como elemento de distorção comunicativa podem criar confusão quando se aumenta a semelhança do trade dress, ocultando diferenças entre os produtos e reduzindo a transparência do mercado (MICELI; PIETERS, 2010). Dessa forma, ampliam-se as chances do consumidor ser induzido à confusão por 'conjuntos imagens' que, apesar de não serem cópias, guardam bastante relação com outro trade dress (BERTOLDO, 2006). Para Cardoso e Bertoldo (2012) a forma mais sutil para levar o consumidor ao erro é por meio da reprodução de elementos que compõem o trade dress de um produto. Dessa forma, o direito do consumidor à informação, $\mathrm{e}$ 
a comunicação competente é negado, e muitas vezes, é preciso que a legislação atue para reduzir as assimetrias (UNDERWOOD; OZANNE, 1998).

Além dessa discussão, destacamos na literatura trabalhos que discutem o conceito de confusão do consumidor (consumer confusion), conforme já mencionado, e que amplia os problemas ocasionados pela semelhança entre embalagens para diferentes aspectos cognitivos, comportamentais e afetivos (MITCHELL; PAPAVASSILIOU, 1997; WALSH; HENNIG-THURAU; MITCHELL, 2007; WALSH; MITCHELL, 2010).

O conceito de confusão do consumidor, apesar da diversidade de definições, pode ser entendido como enganos conscientes e/ou inconscientes dos consumidores no seu processo interpretativo na compra de produtos (AFONSO, 2010). Segundo Walsh e Mitchell (2010) as consequências disso perpassam por abandono, compras equivocadas, insatisfação, 'boca a boca negativo', redução da fidelidade, dentre outras. Os primeiros conceitos de confusão do consumidor relacionavam o fenômeno com apenas a capacidade de processaar informações -foi ampliado para a similaridade física entre as marcas ou informações confusas sobre os produtos (AFONSO, 2010). Dessa forma, Walsh, Hennig-Thurau e Mitchell (2007) e Walsh e Mitchell (2010) apresentam três dimensões: similarity confusion (relacionado com estratégias de imitação), overload confusion (quantidade de informações) e ambiguity confusion (falta de clareza ou informações ambíguas).

Este trabalho avança por considerar de forma mais ampla a importância da embalagem nesse processo e relacionar com ao conceito de trade dress e o modelo de comunicação competente. Apesar de focar diretamente na dimensão da similarity confusion, as embalagens são meios potenciais meios para os demais tipos de confusão apresentadas (overload confusion e ambiguity confusion). De forma ampla os três tipos de confusão podem ser proporcionados (potencializados) por elementos do trade dress.

\section{Modelo normativo de comunicação competente e a distorção comunicativa}

Jürgen Habermas é um filósofo e sociólogo alemão cuja trajetória é marcada como herdeiro e renovador da Teoria Crítica da Escola de Frankfurt. Em decorrência da amplitude da sua obra fazemos neste artigo um corte (bastante simplificador) pelos conceitos de linguagem, comunicação, pretensões de validade e distorção comunicativa. Especialmente, tratando do modelo da pragmática formal.

Conceitualmente, a pragmática-formal investiga as condições possíveis da compreensão mútua, isto é, da comunicação competente (HABERMAS, 2002). E, com isso, sua base reside nos elementos da validade da linguagem cotidiana (regras que um falante competente intuitivamente domina e com as quais produz $\mathrm{e}$ compreende simbólos), seguindo assim, as capacidades de dominar regras estudadas por Chomsky (PINZANI, 2009). Habermas (2002; 2012a) concebe adiante, seguindo Austin e Searle, que nos atos de fala são levantadas pretensões de validade. Antes, de debatê-los apresentamos os tipos de ação.

Habermas (2012a) por meio das diversas abordagens das ciências sociais delineia quatro tipos sociológicos de ação (ou agir): ação teleológica (da qual a ação estratégica é um tipo especial), ação regulada por normas, ação dramatúrgica e ação comunicativa. Nesta pesquisa focamos na ação estratégica e comunicativa. A ação estratégica é voltada para uma finalidade, o sucesso de demandas individuais - podem ser abertas ou veladas (manipulação e comunicação sistemática distorcida). Por outro lado, a ação comunicativa "[...] tem por objetivo o entendimento entre os participantes da discussão" (NOBRE, 2008, p. 21). 
Para apresentar isso do ponto de vista dos participantes, Habermas (2012a) reinterpreta a relação de três mundos lendo Karl Popper e Jarvie como 'mundo objetivo' - "definido como conjunto dos estados de coisas" (HABERMAS, 2012a, p. 167); 'mundo social' - "constituído de um contexto normativo" (HABERMAS, 2012a, p. 170) e 'mundo subjetivo' - "totalidade das vivências subjetivas" (HABERMAS, 2012a, p. 176). Portanto, é possível apresentar uma nova forma de compreender a ação estratégica e a comunicativa. Enquanto, a ação estratégica faz referência apenas ao 'mundo objetivo', na ação comunicativa existe tripla referência (reflexiva) aos mundos (natureza ontológica), isto é, os participantes "[...] referem-se simultaneamente a algo no mundo objetivo, social e subjetivo a fim de negociar definições em comum para as situações" (HABERMAS, 2012a, p. 183).

Em relação a cada mundo existem pretensões de validade que são levantadas: pretensões de verdade (fatos - proposições), correção normativa ou legitimidade (normas sociais) e sinceridade ou veracidade (sentimentos, desejos, intenções e emoções). Dessa forma, a comunicação não se restringe à palavras, gramática e sintaxe (SAMRA-FREDERICKS, 2005), ela se relaciona também à pretensões de validade, sua criticidade e depende do fundo sociocultural - isto é, reinterpretando Husserl, do mundo da vida (lebenswelt): as fundações sobre as quais assentam-se os significados e fonte de interpretações (HABERMAS, 2002, 2012b).

É importante destacar que na maioria das vezes Habermas se refere a apenas três pretensões de validade e em outras quatro (REESE-SCHÄFER, 2010), sendo a quarta denominada inteligibilidade pretensão referente à própria linguagem ou "pressuposto das demais" (REESE-SCHÄFER, 2010, p. 47). Habermas (2012a, p. 147) é pontual ao citar três: "[...] as pretensões de validade (verdade proposicional, correção normativa e veracidade subjetiva)". Podemos entender essa questão da seguinte forma: "a inteligibilidade [...] é a condição da própria compreensão do ato de fala. As outras três pretensões de validade referem-se a três domínios 'ontológicos' diferentes, isto é, a três mundos" (DUTRA, 2005, p. 50). O Quadro 1 sintetiza as pretensões de validade e suas características.

Quadro 1: Pretensões de validade e suas relações.

\begin{tabular}{|c|c|c|c|c|}
\hline $\begin{array}{l}\text { Domínios da } \\
\text { realidade }\end{array}$ & $\begin{array}{c}\text { Modos de } \\
\text { comunicação }\end{array}$ & $\begin{array}{c}\text { Tipo de ato } \\
\text { de fala }\end{array}$ & $\begin{array}{c}\text { Pretensões de } \\
\text { validade }\end{array}$ & $\begin{array}{c}\text { Funções gerais do } \\
\text { discurso }\end{array}$ \\
\hline $\begin{array}{l}\text { "O" mundo de } \\
\text { natureza externa }\end{array}$ & $\begin{array}{c}\text { Cognitivo: } \\
\text { Atitude objetivante }\end{array}$ & Constativo & Verdade & $\begin{array}{l}\text { Representação de } \\
\text { fatos }\end{array}$ \\
\hline $\begin{array}{l}\text { "Nosso" mundo de } \\
\text { sociedade }\end{array}$ & $\begin{array}{l}\text { Interativo: } \\
\text { Atitude conformativa }\end{array}$ & Regulativo & $\begin{array}{c}\text { Correção normativa/ } \\
\text { Adequação/ } \\
\text { Legitimidade }\end{array}$ & $\begin{array}{c}\text { Estabelecimento de } \\
\text { relações } \\
\text { interpessoais } \\
\text { legítimas } \\
\end{array}$ \\
\hline $\begin{array}{l}\text { "Meu" mundo de } \\
\text { natureza interna }\end{array}$ & $\begin{array}{l}\text { Expressivo: } \\
\text { Atitude expressiva }\end{array}$ & Confissões & $\begin{array}{l}\text { Sinceridade/ } \\
\text { Veracidade/ } \\
\text { Autenticidade }\end{array}$ & $\begin{array}{c}\text { Revelação da } \\
\text { subjetividade do } \\
\text { falante }\end{array}$ \\
\hline Linguagem & ----- & ----- & $\begin{array}{c}\text { Inteligibilidade/ } \\
\text { Compreensibilidade }\end{array}$ & ----- \\
\hline
\end{tabular}

Fonte: Adaptado de Habermas (2002, p. 88-102).

Nessa direção, uma condição prévia para a comunicação é que todos os argumentos devem ter igual oportunidade de serem ouvidos, sem assimetrias ou coerção (FORESTER, 1994; CUKIER et al., 2009). Habermas (2012a, 2012b) acredita que essa 'situação ideal de fala' é adiantada (contrafactual) pelos autores no processo comunicativo, pois elas são necessárias na nossa interação comunicativa cotidiana. Na realidade empírica a situação tende a fugir da descrição ideal. Especialmente, nas organizações que "[...] se destacam 
como espaços privilegiados de distorção comunicativa" (VIZEU; CICMANEC, 2013, p. 154). Mesmo assim, a situação ideal de fala (e suas categorias analíticas) serve para julgar atos que estão mais perto ou mais longe da comunicação competente (UNDERWOOD; OZANNE, 1998). Por isso, Cukier et al. (2009) alertam que não é certo supor que Habermas se preocupa apenas com a ideia de uma comunicação ideal, pelo contrário, ele pensa suas condições e contradições conscientes e inconscientes desse modelo, por isso, "[...] na medida em que as reconstruções racionais explicitam as condições da validade de proferimentos, elas também podem explicar casos desviantes e assim adquirir também, [...] uma função crítica" (HABERMAS, 1989, p. 49). Assim, esse referencial pode ser utilizado em investigações sobre manipulação e comunicação sistematicamente distorcida no âmbito do marketing, pois, a partir da noção de comunicação competente é possível explicar as distorções consistindo, daí, a crítica.

Especificamente, utilizamos neste trabalho do conceito de distorção comunicativa conforme interpretação realizada principalmente por Forester (1994), Underwood e Ozanne (1998) e Vizeu e Cicmanec (2013). Assim, dentro da pragmática-formal, cada pretensão de validade está elencada com mecanismos de distorção comunicativa (Quadro 2). Assim, podemos analisar quando eles são burlados ou se afastam do padrão competente (UNDERWOOD; OZANNE, 1998; CUKIER et al., 2009, VIZEU; CICMANEC, 2013).

Quadro 2: Pretensões de validade, dimensão ontológica e distorções.

\begin{tabular}{|c|c|l|}
\hline Pretensão & $\begin{array}{l}\text { Dimensão } \\
\text { ontológica }\end{array}$ & \multicolumn{1}{c|}{ Mecanismos de distorção comunicativa } \\
\hline Verdade & Objetiva & $\begin{array}{l}\text { Mentira; Omissão de informações; adulteração de dados; } \\
\text { interpretação conveniente de dados e informações. }\end{array}$ \\
\hline $\begin{array}{c}\text { Sinceridade } \\
\text { Veracidade }\end{array}$ & Subjetiva & $\begin{array}{l}\text { Demagogia; sentimentalismo exagerado; intenção de } \\
\text { cooperação não comprovada; polidez. }\end{array}$ \\
\hline $\begin{array}{c}\text { Correção normativa } \\
\text { Legitimidade }\end{array}$ & $\begin{array}{l}\text { Desonestidade e transgressão; falso moralismo; menção a } \\
\text { dimensão pública e/ou a valores da sociedade sem } \\
\text { necessidade. }\end{array}$ \\
\hline $\begin{array}{c}\text { Inteligibilidade } \\
\text { Compreensibilidade }\end{array}$ & Compreensiva & $\begin{array}{l}\text { Ambiguidade; retórica; uso de jargões; uso de metáforas; } \\
\text { uso desnecessário de informações; polidez. }\end{array}$ \\
\hline
\end{tabular}

Fonte: Adaptado de Vizeu e Cicmanec (2013, p. 157).

Por fim, acrescentamos que o conceito de comunicação competente está sendo usado como aquela que atende as pretensões de validade, diferentemente do 'competente' em Habermas que se refere a todo sujeito capaz de ação e fala (expressão), portanto, todos possuem competência comunicativa - os sujeitos socializados em uma comunidade linguística (PINZANI, 2009). Por fim, argumentamos que este embasamento teórico nos permite discutir e interpretar as possibilidades de uma comunicação (presencial ou não) em um continuum que varia da comunicação competente à distorção comunicativa. A seguir, destacamos nosso posicionamento epistemológico. 
METODOLOGIA DE PESQUISA

\section{Posicionamento epistemológico}

A pesquisa é definida como qualitativa e descritiva (GODOY, 1995; MINAYO, 2012). Adotamos como posicionamento epistemológico um enfoque hermenêutico e crítico. Vale destacar que a perspectiva reconstrutiva de Habermas (1989, 2012a, 2012b) não se confunde com a hermenêutica, mesmo assim, não deixa de aproveitar dos recursos desta, principalmente, a atitude de participante de processos comunicativos. Logo, a contribuição do artigo se dirige para os processos de interpretação/comunicação sob a ótica dos participantes.

\section{Participantes e coleta dos dados}

O método de pesquisa escolhido para obtenção dos dados foi entrevista em profundidade (TRIVIÑOS, 1987), onde o pesquisador utiliza de um roteiro (que não é rígido) de questões, permitindo iniciar um diálogo com os participantes.

As entrevistas tiveram como primeiras indagações as seguintes questões: Quando você vai comprar um iogurte, o que influencia na sua escolha? Porque você consome iogurte? Você pagaria a mais por algum desses produtos? Por qual deles? (mostrando as embalagens, Figura 1) Você sabe a diferença entre iogurte e bebida láctea fermentada? Essa informação influencia na compra? Após essas primeiras interrogações, em um dado andamento da entrevista, foi explicado a cada um dos entrevistados as diferenças bebida láctea fermentada e iogurte. A partir desse momento algumas perguntas foram repetidas e novas feitas: Você acha que a embalagem de bebida láctea e de iogurte leva o consumidor a confundir os produtos? Você já confundiu? Em sua opinião, as embalagens desses produtos deveriam ser diferentes?

Figura 1: Embalagens de bebida láctea fermentada e iogurte.

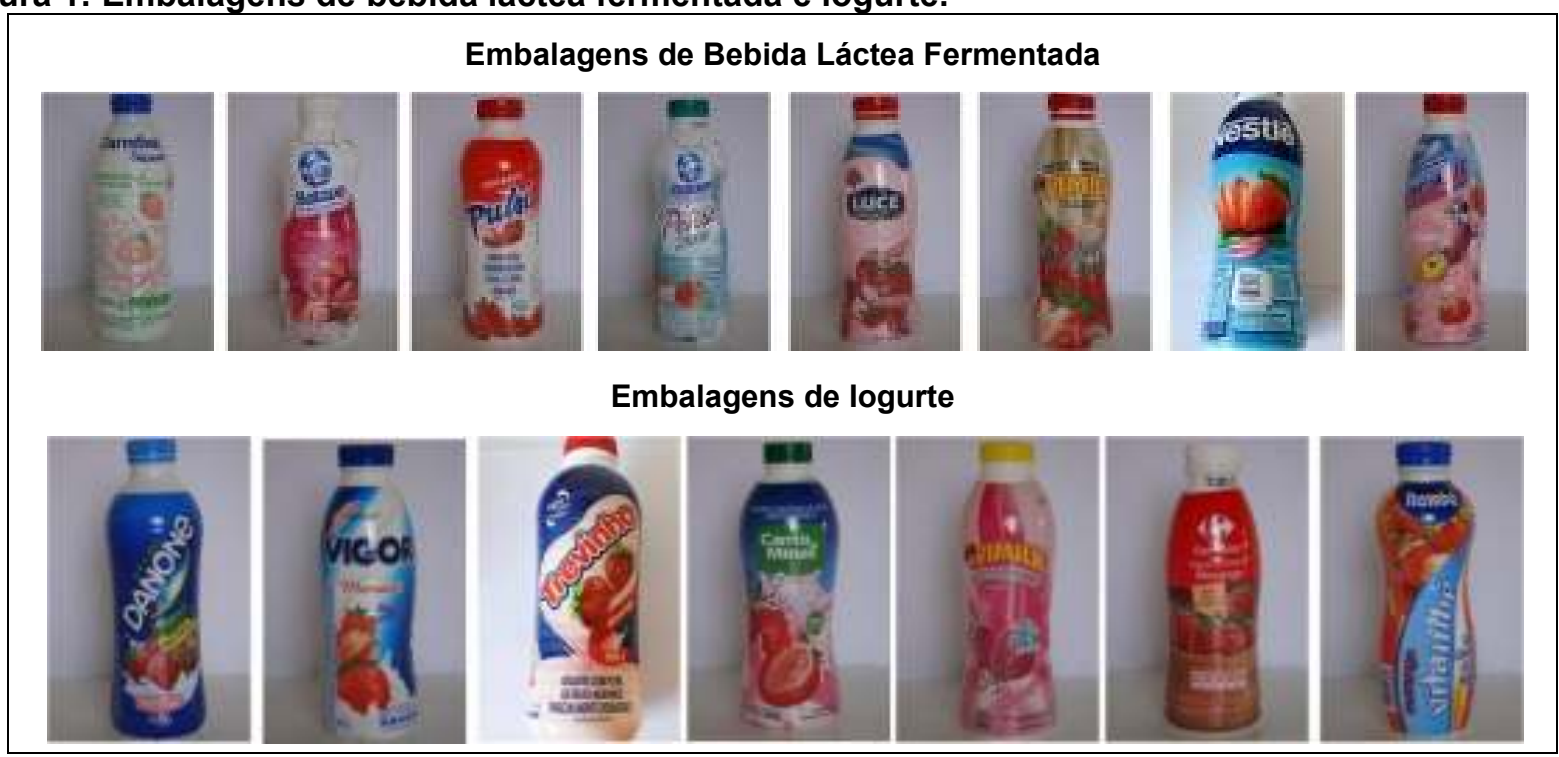

Fonte: Elaborada pelos autores. 
A apresentação das embalagens teve o propósito de visualizar se para os entrevistados (perspectiva dos participantes) as embalagens dos dois produtos são semelhantes ou diferentes - focando na análise dos elementos do trade dress. Para tanto, foi apresentado ao participante uma embalagem de iogurte e outra de bebida láctea fermentada (ambas de $900 \mathrm{ml}$ ) de sabor morango (Figura 1).

A escolha dos participantes foi por conveniência e tipo 'bola de neve' como sugere Malhotra et al. (2005). O contato inicial e a realização do convite de participação foram feitos por telefone. É importante ressaltar que a escolha dos entrevistados também obedeceu ao critério de heterogeneidade, ou seja, buscamos uma amostra composta por indivíduos de diferentes faixas etárias, ocupações e sexos - como indicaram Underwood e Ozanne (1998). Foram realizadas 21 entrevistas em profundidade com consumidores com idade de 18 e 59 anos residentes na cidade de Lavras, Minas Gerais. Acrescentamos que na fase de pré-teste, foram entrevistados cinco indivíduos (20 a 50 anos). A realização do pré-teste tornou possível que algumas perguntas do roteiro fossem reelaboradas e que outras fossem acrescentadas.

No intuito de ampliar a visão sobre a questão da semelhança das embalagens desses dois produtos foram entrevistados 5 (cinco) profissionais atuantes no mercado: um funcionário de laticínio (gerente de marketing), um gerente de supermercado e três publicitários (que prestam serviços para laticínios). As entrevistas, em geral, tiveram duração média de 30 minutos e foram submetidas ao processo de transcrição (mantivemos os aspectos linguísticos das falas).

\section{Interpretação dos dados}

Por meio da pragmática-formal é possível analisar os aspectos da comunicação em marketing e discutir se as embalagens estão desempenhando papel comunicacional competente ou distorcido (UNDERWOOD; OZANNE, 1998; CUKIER et al., 2009; VIZEU; CICMANEC, 2013). Utilizamos para tanto quatro categorias (Figura 2): as três pretensões (verdade, correção normativa e sinceridade) que se referem respectivamente aos mundos objetivo, social e subjetivo, e, a inteligibilidade/compreensibilidade (relativa a linguagem) que aparece como uma pretensão geral de validade (inicial/primeira). No entanto, todo esse processo é permeado por distorções comunicativas (ilustradas externamente pelas setas, mas que também são internas aos próprios atos da fala). 
Figura 2: Framework interpretativo (análise pragmática-formal).

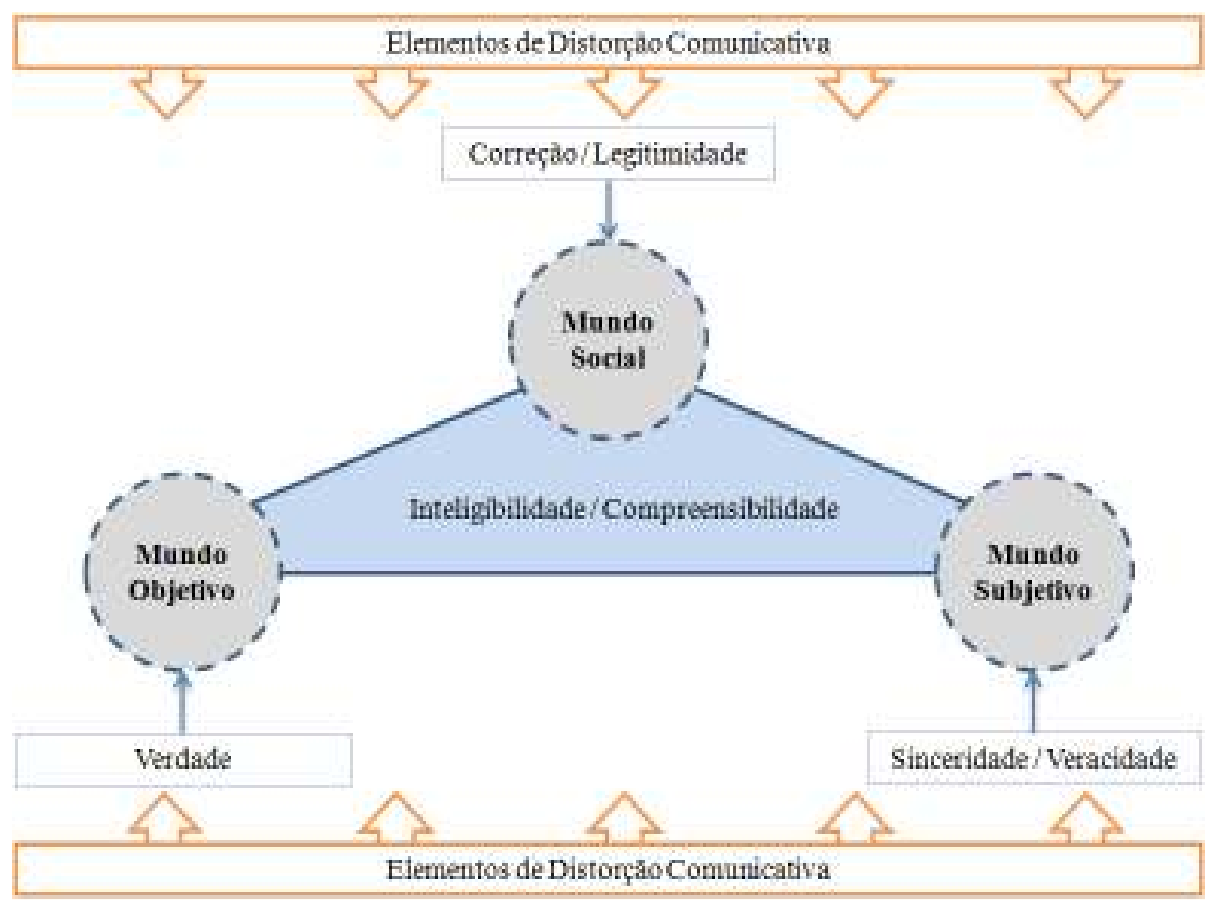

Fonte: Elaborada pelos autores.

A seguir, apresentamos os resultados e discussão, iniciando por um breve contexto do mercado de iogurte e bebida láctea fermentada no Brasil.

\section{RESULTADOS E DISCUSSÃO}

\section{Contexto geral: o mercado de iogurte e bebida láctea fermentada}

Nas últimas décadas houve um aumento expressivo no consumo de leite e derivados (CARVALHO; OLIVEIRA, 2010). E, nesse contexto, as bebidas lácteas fermentadas ganharam importância devido ao fato de que permite ao fabricante reduzir o custo total dos ingredientes utilizando um subproduto líquido resultante da produção de queijos, o soro do leite, constituído basicamente de água (93\%) e somente $7 \%$ de matéria seca. Grande parte desse produto acaba sendo destinado à alimentação animal ou a produção de derivados como a ricota e as bebidas lácteas devido à elevada disponibilidade de seu oferecimento gratuito ou a baixo preço (LIZIEIRE; CAMPOS, 2001). Dentre as bebidas lácteas tem destaque as bebidas lácteas fermentadas que constituem um produto lácteo resultante da mistura do leite e soro (AGÊNCIA NACIONAL DE VIGILÂNCIA SANITÁRIA, 2002).

O iogurte, por sua vez, representa $70 \%$ a $80 \%$ do volume de linha do Brasil e é um produto elaborado da parte 'nobre' do leite - sendo pessoas com hábitos de alimentação saudável responsáveis por parte significativa do consumo desse produto (BARROS; PINTO; FERREIRA, 2002). E ainda este produto é comumente indicado para compor a alimentação de idosos, reposição hormonal e pessoas que em geral precisam ingerir alta quantidade de cálcio. 
É importante estabelecer que a principal diferença entre os dois produtos são os teores de cálcio e fósforo, que o iogurte possui a mais, e sódio, que possui a menos (NEPA-UNICAMP, 2011). Dadas essas questões, a bebida láctea fermentada e o iogurte, embora com características sensoriais semelhantes, possuem propriedades nutricionais diferentes (LUZ, 2008). Adiante, existe também um alto nível de semelhança entre as embalagens (VIEIRA et al., 2015). Assim, os processos interpretativos dos consumidores durante a compra podem se tornar confusos e distorcidos, dificultando a distinção entre um produto e outro.

\section{Entre a Comunicação Competente e a Distorção Comunicativa}

\section{A pretensão de validade da verdade}

À medida que se iniciam as análises das falas dos entrevistados, é possível verificar que a maioria não sabe diferenciar bebida láctea fermentada de iogurte. Alguns, respondem ainda, que se quer sabiam da existência de um produto tão semelhante, ou seja, para os respondentes (consumidores) deste estudo, de acordo com o significado que atribuíam as embalagens na gôndola, a bebida láctea fermentada não existe.

Você está me falando que essas embalagens aqui são de produtos diferentes? Sempre que vou ao supermercado penso em comprar iogurte, nunca olho e falo 'vou comprar bebida láctea fermentada', nem sabia que isso existia. Para mim era tudo iogurte mesmo só mudava a marca (Consumidor 13, 38 anos).

Como a verdade é, para Habermas (1989, 2012a, 2012b), pressuposta pelos sujeitos nas suas interações (que podem ser virtuais como no caso das embalagens; isto é, não presenciais) constatamos que os consumidores acreditavam na verdade (fatos) das embalagens - como sendo iguais (mesmo produto/mesmo trade dress).

Com relação às letras pequenas Underwood e Ozzane (1998) também identificaram essas distorções e afirmaram que isso não atende a pretensão de verdade, dificultando consequentemente uma prática de comunicação competente. Assim, sobre a confusão do consumidor é preciso considerar que a similaridade é um pré-requisito de confusão (WALSH; MITCHELL, 2010). E, a quantidade de produtos similares pode proporcionar indecisão no processo de compra (SCHWEIZER; KOTOUC; WAGNER, 2006; WALSH; HENNIG-THURAU; MITCHELL, 2007).

Para identificar outro ponto de vista foram entrevistados profissionais da área de marketing e publicidade. É possível visualizar em seus discursos a orientação para o êxito da comunicação e não para o entendimento dos argumentos e enunciados. Por meio das falas aparece a ideia de que o consumidor pode ser 'iludido' e a empresa alcançar melhores resultados em termos de venda das bebidas lácteas. Pelo visto, o desconhecimento faz parte da estratégia.

[...] se as duas estão expostas na mesma gôndola, uma ao lado da outra a pessoa já assimila que é o mesmo produto [...] mesmo se estiver grande [a denominação de venda], não só a embalagem, mas o posicionamento da gôndola também confunde (Publicitário 3, 34 anos). 
Olha são produtos com propriedades nutricionais semelhantes. Claro que o iogurte acaba sendo um pouco melhor, [...]. Ela tem um custo mais baixo pra gente e acaba vendendo preço a preço na gôndola e às vezes um pouco mais barato. Ela ficar perto e parecida com iogurte compensa e não faz mal para saúde de ninguém. (Gerente de Marketing, 27 anos).

Percebemos na fala do gerente que mesmo ocultando informações ou as deixando de difícil acesso, essa prática é positiva para as empresas - o mesmo destaca ganhos econômicos com isso fazendo a relação entre custo e preço de venda. Por meio das falas destes expõe-se a ideia de que o consumidor deve ser iludido e que com isso a empresa alcança melhores resultados em termos de venda das bebidas lácteas. Constatamos que neste tipo de comunicação, orientada para o resultado, o interlocutor é um meio para se atingir um resultado esperado (VIZEU, 2009; HABERMAS, 1989; 2012a), e o meio mais rápido para mobilizálo no atingimento do resultado é através da distorção da comunicação. Como exemplo, é possível visualizar outras falas:

Eu vou te falar uma coisa, se mudar a embalagem e colocar que tem soro, não vende. E a margem dela para nós aqui é bem mais interessante. Agora quanto ao valor de nutrição isso aí eu não sei te falar nada não (Gerente de Supermercado, 41 anos).

As embalagens desses dois produtos serem iguais é para o consumidor assimilar um com outro mesmo. Agora que é uma vantagem ela [embalagem] ser parecida com iogurte isso sem dúvidas. Se tivesse uma lei para alterar, a gente alteraria, mas por conta própria é dar um tiro no pé (risos) (Gerente de Marketing, 27 anos).

Dessa forma, não se constata adequação da pretensão de verdade, onde, ao que tudo indica as “[...] práticas gerenciais são fortemente condicionadas para o êxito. [...]. Consumidores devem comprar cada vez mais [...]" (VIZEU, 2009, p. 9). A confusão causada pelas orientações das ações (entre a encontrada e a considerada como verdadeira) causa uma ação veladamente estratégica. Finalmente, a busca por uma comunicação em que a pretensão de verdade (possa ser aceita) é indicada pelo saber cotidiano e competente de um consumidor: "essas embalagens são iguais [iogurte e bebida láctea], deviam ser diferentes, assim o consumidor iria saber o que está comprando" (Entrevistada 6, 53 anos).

\section{A pretensão de validade da sinceridade ou veracidade}

No contexto das embalagens a pretensão da sinceridade se relaciona com a intenção da empresa com as embalagens, isto é, com o que ela deseja expressar (UNDERWOOD; OZANNE, 1998). Ou seja, a pretensão de sinceridade é negada quando os consumidores não confiam nas intenções expressas pelos fabricantes. E, so pode ser testada diante do comportamento do falante, isto é, se suas ações correspondem realmente as intenções manifestadas (HABERMAS, 2012a). 
No caso desta pesquisa os consumidores e os publicitários consideram que a intenção dos fabricantes era realmente ocultar/enganar (contrapondo a pretensão de sinceridade).

Que ele [o produtor de bebida láctea] está enganando ele sabe disso. [...] ele faz isso proposital. [...] Quem precifica é o próprio produtor, então, eles tiram uma vantagem boa em cima disso [...] mas como o consumidor não reclama, não acha ruim, não tem nada o que mudar (Publicitário 2,32 anos).

Tanto [para] o governo como grandes corporações ou quem tá lá no poder não é interesse, então pra eles é um bom negócio (Consumidora 1, 23 anos).

Pelo indicado, a deformação no processo comunicativo é apontada pelos consumidores como deliberada - a intenção das empresas é ter uma comunicação não transparente por meio da semelhança entre os trade dress que levam os consumidores a se confundirem e realizaram compras equivocadas (UNDERWOOD; OZANNE, 1998; WALSH; HENNIG-THURAU; MITCHELL, 2007; WALSH; MITCHELL, 2010). Além disso, revela a orientação estratégica da ação: "[...] do ponto de consumidor eu preferiria que fosse bem definido a diferença de um para outro [...] Agora profissionalmente falando nunca. [...] Investir nas vendas da bebida láctea é bastante interessante" (Publicitária 2, 32 anos). Isto é, assume a possição do sujeito que apenas deseja maximizar seus ganhos na relação com o alter. $O$ consumidor indica também que a intenção do produtor é ser realmente instransparente.

Se você colocar bem gritante, letras garrafais identificando bebida láctea e iogurte, isso causaria curiosidade pra saber a diferença. E essa busca de informação não é interesse de grande corporação (Consumidor 13, 38 anos).

A violação da pretensão da sinceridade pode ter implicações diversas, até mesmo para as empresas como a redução da fidelidade à marca, conforme revelado por Underwood e Ozanne (1998). Mas, enquanto o consumidor não possui acesso a isso a empresa mantém um formato de comunicação permeado por assimetrias. Especificamente, a manipulação ocorre quando o consumidor acredita que as empresas não estão agindo estrategicamente, isto é, que a forma como elaboram as embalagens e expõem bebidas lácteas e iogurtes não possui intenção de enganar ou ocultar informações e intenções. Este não parece ser o caso desta pesquisa, onde para publicitários e consumidores, as deformações no processo comunicativo são indicadas como intencionais.

\section{A pretensão de validade da adequação normativa ou legitimidade}

A comunicação ocorre em contexto normativo compartilhado (regras e normas), onde se levanta também a pretensão de validade da adequação normativa ou legitimidade (HABERMAS, 1989, 2012a, 2012b). Por mais que a legislação obrigue que se coloque que a bebida láctea fermentada contém soro de leite e que esta informação esteja realmente presente nas embalagens dos produtos que estão disponíveis no mercado, quando explicado detalhadamente para o consumidor que esse produto 'não é iogurte' a intenção de compra é negativa - eles se sentem enganados até mesmo em relação a legislação.

A declaração obrigatória dos nutrientes e ingredientes nos rótulos presentes na legislação de alimentos não parece ser suficiente para que os consumidores escolham conscientemente um produto em 
detrimento de outro. No que diz respeito à denominação de venda (bebida láctea fermentada/iogurte), a legislação exige que se deva constar na parte principal a denominação de venda do alimento e, nesse caso, todos os produtos analisados para este trabalho estavam com as informações corretamente expostas de acordo com o Código de Defesa do Consumidor.

Mesmo assim, seguindo as normatizações existentes, os consumidores se expressam descontentes: "[...] a gente vê tanto caso por aí de marca brigando na justiça porque é parecida, mas quando é de interesses deles ninguém faz nada [...] o governo tinha que intervir do jeito que é não está certo não!" (Consumidor 14, 35 anos). Os consumidores parecem não aceitar as pretensões de legitimidade levantadas. Indicamos que é na falta de normatizações mais específicas que existem lacunas para que as embalagens (trade dress) não sejam totalmente transparentes e causem processos distorcidos. Por isso, o gerente entrevistado afirmou: "[...] nós seguimos a legislação" e um publicitário complementa: "[para mudar] só se fosse através de uma lei" (Publicitário 2, 32 anos). A legislação é levantada como argumento para legitimar o processo de venda destes produtos. Contudo, conforme Vizeu (2009) um processo comunicativo competente se baseia em uma pluralidade ontológica, a adequação apenas à legislação não faz a comunicação ser competente (HABERMAS, 2012a, 2012b) - revela a necessidade de considerar todas as pretensões de validade conjuntamente no estudo das embalagens.

Outra consumidora é novamente clara ao afirmar que deveriam ser visivelmente diferentes e indica que a inclusão de informações pode dar suporte à adequação normativa.

Acho que as embalagens deveriam ser diferentes, mostrar mais. Para o consumidor ficar mais consciente do que está comprando. [...] Porque eu mesma, de óculos, não consigo enxergar muito claramente (Consumidora 7, 54 anos).

Mesmo que o objetivo ao utilizar o trade dress seja uma tentativa de diferenciar um produto ou marca das demais, no que diz respeito ao objeto de estudo em pauta, as semelhanças são notáveis sejam entre marcas diferentes ou produtos da mesma marca. No entanto, como indicado, isso não fere as normas existentes, mesmo diante da desconfiança dos consumidores ao constatar a semelhança. Assim, o estudo também pode direcionar (chamar) para a construção de políticas públicas regulatórias e que considerem essas dimensões nos processos comunicativos e informacionais das embalagens, em especial, no seu trade dress. De acordo com o relato de um dos profissionais da agência de publicidade que trabalha para um laticínio de grande porte na região, do ponto de vista da empresa que comercializa esses dois produtos, manter a embalagem de bebida láctea fermentada o mais parecido possível com o iogurte constitui uma boa estratégia de mercado: "[...] é normal que sabendo as diferenças o consumidor se sinta enganado, mas cabe a ele procurar se informar, o laticínio segue a legislação corretamente" (Publicitário1, 28 anos) e usa a legislação para 'validar' a posição da empresa. 


\section{A pretensão da linguagem: compreensibilidade ou inteligibilidade}

A compreensibilidade ou inteligibilidade é importante para os processos de interpretação das informações disponibilizadas nas embalagens. No caso da linguagem utilizada nas embalagens esta pretensão é violada quando o consumidor não compreende a mensagem que é transmitida ou as informações que são passadas (UNDERWOOD; OZANNE, 1998). Pela fala dos entrevistados é possível perceber que a expressão 'bebida láctea fermentada' é distante do conhecimento dos consumidores - não faz parte de seu repertório de interpretações e construção de significados. Dentre os 21 consumidores entrevistados apenas uma conhecia a diferença entre esse produto e o iogurte, mesmo assim, se equivocou no momento da entrevista: "Acho que eles já fazem de propósito está escrito tão apagadinho aqui" (Consumidora 2, 24 anos).

O públicitário, por outro lado, coloca que isso não diz respeito à empresa, mas à falta de competência (conhecimento) e de compreensão do consumidor, e, na mesma frase reconhece que as embalagens são parecidas e com posicionamento próximo na gôndula. Sobre a confusão do consumidor a literatura considera que até mesmo a forma com que as embalagens estão dispostas nas gôndulas pode gerar confusão (AFONSO, 2010).

Não é para se sentir enganado. Eu acho que é muito mais uma falta de conhecimento de quem não trabalha com essa área e nunca produziu esse tipo de produto, que não tem noção dessa diferenciação do que uma forma de enganar a população usando a embalagem parecida e um posicionamento próximo na gôndola (Publicitário 1, 28 anos).

Assim, ssegundo Habermas (1989, 2012a, 2012b), a comunicação deve se fazer com signos compreensíveis, isso não se observa no caso estudado. Por exemplo, a tipografia utilizada e letras pequenas, geralmente em uma das laterais das embalagens, dificulta a visualização e contribui para confundir um produto com outro.

É importante destacar que a utilização do soro de leite na composição de alguns produtos é crescente na indústria de alimentos. Ele tem valor nutritivo, custo mais baixo, além de ser uma alternativa para o produtor reutilizar algo que seria extremamente poluente ao meio ambiente. Porém, no que diz respeito a compreensão (compreensibilidade ou inteligibilidade), há desconhecimento também dos consumidores do uso de soro em alimentos - e as empresas não fazem questão de informar transparentemente (o que tende a manter as assimetrias e não reduzi-lás).

Já comprei enganada sim, certamente que já. Agora que você me explicou o que é bebida láctea não pagaria a mais, [...] nem compraria [...]. Porque eu não sou porco. Soro é para engordar porco! (Consumidora 2, 24 anos).

Eu não vejo problema em ser soro de leite. [...] a questão é o produto que está sendo vendido, pode ser um produto soro, um resto que sobra [...] se é iogurte, se é bebida láctea, não importa [...] Se eu estou indo comprar uma coisa, é aquilo que eu quero comprar. Se eu quiser soro eu vou lá e compro (Consumidor 5, 26 anos). 
Algumas consequências são relatadas nos casos de confusão do consumidor, especialmente, no que diz respeito a realização de compras equívocas, insatisfação e propagação de opiniões negativas sobre a marca (WALSH; MITCHELL, 2010). Pela fala desses consumidores é possível observar indignação em relação ao produto com soro que está sendo oferecido. Embora seja perceptível esse sentimento de revolta, vale pontuar que não se pretende criticar a venda da bebida láctea fermentada neste trabalho, apenas que ela tenha seu espaço e se fortaleça na indústria de laticínio, mas de forma justa e honesta com o consumidor (verdadeira, sincera, legítima e compreensível), ou conforme, afirmou o segundo entrevistado: que o consumidor possa comprar o que se dispôs a comprar.

Uma das formas de evitar que os consumidores cometam equívocos no momento de comprar é diferenciando tamanhos e formas, assim seria possível fazer comparações entre os produtos, atendendo à norma de compreensibilidade.

[...] a embalagem deveria ser diferenciada. Eu acho que tanta gente compra gato por lebre em tudo. [...] acho que seria legal mudar a embalagem colocar alguma coisa que a gente note de longe, não sei o que, mas do jeito que está confunde (Consumidora 1, 23 anos).

Quando um fabricante de bebida láctea fermentada coloca a denominação de venda na lateral da embalagem e a informação obrigatória 'contém soro de leite' em uma localização pouco favorável à visualização, embora a norma da legitimidade não seja infringida claramente, a norma da compreensibilidade é violada. Finalmente, indicamos que usando de um vocabulário competente, nem especializado demais, tampouco vago, as empresas podem se comunicar com seus consumidores de forma competente (VERNUCCIO; COZZOLINO; MICHELINO, 2010).

\section{CONCLUSÃO}

A presente pesquisa identificou (a partir dos participantes das práticas de consumo) aspectos e graus de semelhança entre as embalagens de iogurtes e bebidas lácteas fermentadas, revelando que os consumidores não diferenciam esses produtos e realizam compras equivocadas induzidas pelas características de suas embalagens e da semelhança entre o trade dress das mesmas. As semelhanças entre as embalagens de bebidas lácteas e iogurtes são indicadas pelos consumidores como deliberadas, e, não geram problemas para as empresas, pois a maioria dos consumidores não consegue perceber. Além disso, do lado da empresa, pelas entrevistas, ao que parece quanto mais parecido com o iogurte melhor, fato que reflete inclusive no posicionamento do produto nas gôndolas dos supermercados. Isso constitui uma 'boa estratégia' (no sentido da ação estratégica). Os produtores exploram o desconhecimento dos consumidores trazendo resultados que julgam satisfatórios para os laticínios e o comércio destes produtos. Do lado dos consumidores, foi possível perceber que eles não sabem diferenciar esses produtos e as características de suas embalagens realmente os induzem a realizar compras equivocadas; assim, foram relatados vários casos de confusão do consumidor, principalmente, relacionadas a semelhança entre as embalagens. 
Mesmo que a saída da distorção e manipulação comunicativa seja caminhar na direção de interações livres de mecanismos sistêmicos (HABERMAS, 1989, 2012a, 2012b), a regulação democraticamente legitimada (normas, regulamentos, etc) se apresenta como possibilidade de proteger as interações cotidianas dos consumidores (na relação com o mercado). Portanto, uma das implicações deste trabalho reside na sugestão da criação de regras restritivas que impeçam a cópia do trade dress em produtos que possuam embalagens parecidas e são sensorialmente semelhantes, ou ainda que evitem características que levem os consumidores a confundirem-se, considerando todas as pretensões de validade e a inteligibilidade (pretensão geral).

Argumentamos que uma comunicação competente pode beneficiar também as empresas, desde que elas se pautem em propostas adequadas às pretensões de validade. Assim, cabe destacar que neste trabalho não se pretende criticar a produção de bebidas lácteas fermentadas. O propósito é justamente o contrário, que de forma justa com o consumidor ela tenha seu espaço no mercado, pois, é uma alternativa de consumo sustentável - o desenvolvimento de uma bebida láctea fermentada é uma alternativa bastante inovadora para o aproveitamento do soro pelas indústrias lácteas. É na tentativa de estabelecer essa relação que os fabricantes podem encontrar um equilíbrio entre as necessidades de ambos de forma que as embalagens apresentem conteúdos intersubjetivamente reconhecidos e aceitos pelos participantes das práticas de compra e venda.

Como limitações da pesquisa, destacamos que é preciso considerar que as distorções "[...] podem não ser deliberadas e calculadas" (FORESTER, 1994, p. 141), mesmo que as indicações levem para essa afirmação. Além disso, é preciso ter cuidado para não "[...] generalizar excessivamente casos particulares" (HABERMAS, 1989, p. 49). Outras pesquisas na mesma direção podem elucidar melhor as distorções/manipulações, bem como identificar modelos competentes de comunicação com os consumidores. Adiante, utilizamos a proposta da pragmática-formal de Habermas, sendo possível ampliar na direção das considerações realizadas por Goldkuhl (2000) que amplia as categorias considerando nove pretensões gerais da comunicação: sinceridade; alinhamento à norma; correção descritiva; argumentatividade, relevância do destinatário; respeitosidade; deliberação; adequação dialógica e inteligibilidade.

Como agenda de pesquisa indicamos: i) aplicar o quadro da pragmática-formal com pesquisas com outras embalagens, especialmente, considerando as ampliações realizadas por Goldkuhl (2000); ii) utilizar essas referências para investigar campanhas e peças publicitárias; iii) apresentar uma perspectiva teórica reconstrutiva para o marketing que possa oferecer uma matriz epistemológica hermenêutica e crítica e iv) ampliar as discussões apresentadas por meio da literatura sobre confusão do consumidor (consumer confusion) ainda pouco debatida no Brasil. Enfim, pesquisas voltadas para uma perspectiva no marketing que se proponha a desvelar manipulações, confusões, comunicações distorcidas e seus efeitos - contribuindo com formas de comercialização e consumo mais sustentáveis, éticas e comunicativas. 


\section{REFERÊNCIAS}

ABREU, L. R.; GAJO, A. A. Tecnologia de produtos lácteos. Lavras: FAEPE, 2012.

AFONSO, C. W. A confusão no processo de escolha do consumidor. 2010. 216 f. Tese (Doutorado em Administração) Fundação Getulio Vargas, Rio de Janeiro, 2010.

AGÊNCIA NACIONAL DE VIGILÂNCIA SANITÁRIA - ANVISA. Resolução RDC n² 259, de 20 de setembro de 2002. Aprova o regulamento técnico sobre rotulagem de alimentos embalados. Diário Oficial da União, Brasília, DF, 23 set. 2002.

ALVESSON, M. Critical theory and consumer marketing. Scandinavian Journal of Management, v. 10, n. 3, p. 291-313, 1994.

BARROS, G. A.; PINTO, M. O.; FERREIRA, M. T. A indústria de laticínios brasileira e mineira em números. Belo Horizonte: Instituto de Desenvolvimento Industrial de Minas Gerais, 2002.

BERTOLDO, M. R. A satisfação dos clientes internos e o comprometimento organizacional: um estudo à luz do modelo ASH nas indústrias alimentícias do RN. 2006. 88 f. Dissertação (Mestrado em Administração) - Universidade Federal do Rio Grande do Norte, Natal, 2006.

BROWNLIE, D. et al. The new marketing myopia: critical perspectives on theory and research in Marketing. European Journal of Marketing, Bradford, v. 28, n. 3, p. 6-12, 1994.

CARDOSO, F. B. J.; BERTOLDO, T. Embalagem de marcas próprias: elementos de semelhança e diferença na construção gráfica. A Cientificidade da Comunicação, v. 19, n. 2, p. 121-133, 2012.

CARVALHO, G. R.; OLIVEIRA, C. Consolidação na indústria de laticínios: o Brasil no contexto internacional. Agroanalysis, v. 33, p. 20-23, 2010.

CHANDON, P.; WANSINK, B. Is food marketing making us fat? A multi-disciplinary review. Foundations and Trends in Marketing, Washington, v. 5, n. 3, p. 113-196, 2011.

CUKIER, W. et al. A critical analysis of media discourse on information technology: preliminary results of a proposed method for critical discourse analysis. Information Systems Journal, v. 19, n. 2, p. 175-196, 2009.

DANIEL, D. A. Litígio envolvendo conjunto-imagem (Trade Dress) no Brasil: a área nebulosa de proteção da propriedade intelectual. 2006. Disponível em: <http://www.daniel.adv.br/port/articlespublications/denisdaniel/trade_dress.pdf>. Acesso em 20 de nov. de 2015.

DUTRA, D. J. V. Razão e consenso em Habermas: a teoria discursiva da verdade, da moral, do direito e da biotecnologia. Florianópolis: Ed. UFSC, 2005.

FARIA, A. Crítica e cultura em marketing: repensando a disciplina. Cadernos EBAPE. BR, v. 4, n. 3, p. 01-16, 2006.

FORESTER, J. Teoria crítica e análise organizacional. Plural, v. 1, p. 131-148, 1994.

GHIDOSSI, R. et al. The influence of packaging on wine conservation. Food Control, Guildford, v. 23, n. 2, p. 302-311, 2012.

GODOY, A. S. Introdução à pesquisa qualitativa e suas possibilidades. Revista de Administração de Empresas, v. 35 , n. 2, p. 57-63, 1995.

GOLDKUHL, G. The validity of validity claims: An inquiry into communication rationality. In: SCHOOP, M.; QUIX, C. (Org.). Proceedings of the Fifth International Workshop on the Language-Action Perspective on Communication Modeling (LAP 2000). Aachen, 2000. p. 14-16.

HABERMAS, J. Consciência moral e agir comunicativo. Rio de Janeiro: Tempo Brasileiro, 1989.

HABERMAS, J. Direito e democracia: entre facticidade e validade. Rio de Janeiro: Tempo Brasileiro, 1997.

HABERMAS, J. Racionalidade e comunicação. Lisboa: Edições 70, 2002.

HABERMAS, J. Teoria do agir comunicativo: racionalidade da ação e racionalização social. São Paulo: Martins Fontes, 2012a.

HABERMAS, J. Teoria do agir comunicativo: sobre a crítica da razão funcionalista. São Paulo: Martins Fontes, $2012 b$.

LIZIEIRE, R. S.; CAMPOS, O. F. O soro de queijo 'in natura' na alimentação do gado de leite: instrução técnica para o produtor de leite. Juiz de Fora: Embrapa Gado de Leite, 2001.

LUZ, L. M. P. Avaliação do envase a quente de uma bebida láctea na conservação da temperatura ambiente. 2008. 53 f. Dissertação (Mestrado em Ciência dos Alimentos) - Universidade Federal de Viçosa, Viçosa, 2008.

MALHOTRA, N. K. et al. Introdução à pesquisa de marketing. São Paulo: Pearson Prentice Hall, 2005. 
MICELI, G. N.; PIETERS, R. Looking more or less alike: determinants of perceived visual similarity between copycat and leading brands. Journal of Business Research, v. 63, n. 11, p. 1121-1128, 2010.

MINAYO, M. C. S. Análise qualitativa: teoria, passos e fidedignidade. Ciência \& Saúde Coletiva, v. 17, n. 3, p. 621-626, 2012.

MITCHELL, V. W.; PAPAVASSILIOU, V. Exploring consumer confusion in the watch market. Marketing Intelligence \& Planning, v. 15, n. 4, p. 164-172, 1997.

NEPA-UNICAMP. Tabela Brasileira de Composição de Alimentos - TACO. 4. ed. Campinas: Nepa-Unicamp, 2011. Disponível em: <http://www.unicamp.br/nepa/taco/>. Acesso em: 20 set. 2015.

NOBRE, M. Introdução. In: NOBRE, M.; TERRA, R. (Org.). Direito e democracia: um guia de leitura. São Paulo: Malheiros, 2008. p. 15-35.

PINZANI, A. Habermas. São Paulo: Artmed Editora, 2009.

REESE-SCHÄFER, W. Compreender Habermas. 3. ed. Petrópolis: Vozes, 2010.

SAMRA-FREDERICKS, D. Strategic practice, discourse and the everyday interactional constitution of power effects. Organization, v. 12, n. 6, p. 803-841, 2005.

SCHWEIZER, M,; KOTOUC, A. J.; WAGNER, T. Scale development for consumer confusion. Advances in Consumer Research, v. 33, p. 184-190, 2006.

SIEBENEICHLER, F. B. Apresentação à edição brasileira. In: HABERMAS, J. Teoria do agir comunicativo: racionalidade da ação e racionalização social. São Paulo: Martins Fontes, 2012. V. 1, p. vii-xxvi.

TRIVIÑOS, A. N. S. Introdução à pesquisa em ciências sociais: a pesquisa qualitativa em educação. São Paulo: Atlas, 1987.

UNDERWOOD, R. L.; OZANNE, J. L. Is your package an effective communicator? A normative framework for increasing the communicative competence of packaging. Journal of Marketing Communications, v. 4, n. 4, p. 207-220, 1998.

VAN HOREN, F.; PIETERS, R. When high-similarity copycats lose and moderate-similarity copycats gain: the impact of comparative evaluation. Journal of Marketing Research, v. 49, n. 1, p. 83-91, 2012.

VERNUCCIO, M.; COZZOLINO, A.; MICHELINI, L. An exploratory study of marketing, logistics, and ethics in packaging innovation. European Journal of Innovation Management, v. 13, n. 3, p. 333-354, 2010.

VIEIRA, K. C. et al. How does packaging influence consumer behavior? a multidisciplinary bibliometric study. International Business Research, v. 8, n. 5, p. 66-80, 2015.

VIEIRA, K. C.; ALCÂNTARA, V. D. C.; TONELLI, D. F. A influência das embalagens no comportamento do consumidor de alimentos. In: SEMINÁRIO EM ADMINISTRAÇÃO, 17., 2014, São Paulo. Anais... São Paulo: SEMEAD, 2014.

VIEIRA, R. S. G. et al. O Conhecimento do marketing sob os olhos da teoria crítica. In: Encontro da ANPAD, 26., 2002, Salvador. Anais... Salvador: ANPAD, 2002.

VIZEU, F. Racionalidade administrativa e distorção comunicativa nas organizações contemporâneas. In: Encontro da ANPAD, 33., 2009, Rio de Janeiro. Anais... Rio de Janeiro: ANPAD, 2009.

VIZEU, F.; CICMANEC, É. R. A música que encanta, o discurso que aprisiona: a distorção comunicativa em uma loja de departamentos. Cadernos EBAPE.BR, v. 11, n. 1, p. 149-164, 2013.

WALSH, G.; HENNIG-THURAU, T.; MITCHELL, V. W. Consumer confusion proneness: scale development, validation, and application. Journal of Marketing Management, v. 23, n. 7-8, p. 697-721, 2007.

WALSH, G.; MITCHELL, V. W. The effect of consumer confusion proneness on word of mouth, trust, and customer satisfaction. European Journal of Marketing, v. 44, n. 6, p. 838-859, 2010. 